\title{
CARBONO ORGÂNICO TOTAL E AGREGAÇÃO DO SOLO EM SISTEMA DE PLANTIO DIRETO AGROECOLÓGICO E CONVENCIONAL DE CEBOLA
}

\author{
Arcângelo Loss ${ }^{(1) *}$, Alex Basso ${ }^{(2)}$, Bruno Salvador Oliveira ${ }^{(2)}$, Leôncio de Paula Koucher ${ }^{(2)}$, \\ Rodolfo Assis de Oliveira ${ }^{(2)}$, Claudinei Kurtz ${ }^{(3)}$, Paulo Emílio Lovato ${ }^{(1)}$, Pierre Curmi ${ }^{(4)}$, \\ Gustavo Brunetto( ${ }^{(5)}$ e Jucinei José Comin ${ }^{(1)}$
}

\footnotetext{
(1) Universidade Federal de Santa Catarina, Centro de Ciências Agrárias, Departamento de Engenharia Rural, Florianópolis, Santa Catarina, Brasil.

(2) Universidade Federal de Santa Catarina, Centro de Ciências Agrárias, Departamento de Engenharia Rural, Programa de Pós-Graduação em Agroecossistemas, Florianópolis, Santa Catarina, Brasil.

(3) Empresa de Pesquisa Agropecuária e Extensão Rural de Santa Catarina, Ituporanga, Santa Catarina, Brasil.

(4) AgroSup Dijon, UMR 1347 Agroécologie, BP 87999, 26 Bd du Dr Petitjean, 21079 Dijon Cedex, França.

(5) Universidade Federal de Santa Maria, Centro de Ciências Rurais, Departamento de Solos, Santa Maria, Rio Grande do Sul, Brasil.

* Autor correspondente.

E-mail: arcangelo.loss@ufsc.br
}

\section{RESUMO}

Decorrente dos sistemas de manejo empregados no solo, como o sistema de preparo convencional (SPC) versus o sistema de plantio direto de hortaliças (SPDH), modificações nos atributos edáficos ocorrem; por exemplo, nos índices de agregação do solo e seu teor de carbono orgânico total (COT). Objetivaram-se quantificar os teores de COT e avaliar os índices de agregação do solo e a distribuição dos agregados por classes de diâmetro sob cultivo de cebola em SPDH e SPC, comparados a uma área de mata adjacente em Ituporanga, SC. Os tratamentos constituíram-se da semeadura de plantas de cobertura, solteiras e consorciadas, em SPDH: vegetação espontânea (VE); 100 \% aveia; 100 \% centeio; 100 \% nabo-forrageiro; consórcio de nabo-forrageiro (14\%) e centeio (86 \%); e consórcio de nabo-forrageiro (14\%) e aveia (86 \%). Adicionalmente, foram avaliadas uma área de cultivo de cebola em SPC por \pm 37 anos e uma área de mata (floresta secundária; \pm 30 anos), ambas adjacentes ao experimento. Em setembro de 2013, cinco anos após a implantação dos tratamentos com plantas de cobertura, foram coletadas amostras indeformadas do solo nas camadas de 0-5, 5-10 e 10-20 cm e separados os agregados para avaliar a estabilidade via úmida. Nos agregados, foi quantificado o COT; 
após a separação em classes de diâmetro $(8,00 \mathrm{~mm}>\emptyset \geq 0,105 \mathrm{~mm})$, calcularam-se o diâmetro médio ponderado (DMP) e o geométrico (DMG) dos agregados; a distribuição deles em macroagregados $(\emptyset \geq 2,0 \mathrm{~mm})$, mesoagregados $(2,0>\emptyset \geq 0,25 \mathrm{~mm})$ e microagregados $(\emptyset<0,25 \mathrm{~mm})$; e o seu índice de sensibilidade (IS). Os dados foram submetidos à análise de variância e de componentes principais (ACP). Os maiores teores de COT foram encontrados na área de mata $\left(52,83 ; 37,77\right.$; e 26,70 $\mathrm{g} \mathrm{kg}^{-1}$, respectivamente para 0-5, 5-10 e 10-20 cm); e os menores, no SPC $\left(18,23 \mathrm{~g} \mathrm{~kg}^{-1}, 0-5 \mathrm{~cm}\right)$. Os tratamentos com plantas de cobertura, solteiras ou consorciadas, não apresentaram diferenças entre si $(p \leq 0,05)$ para o COT, nem em relação à área testemunha (VE). O SPC apresentou os menores índices de DMP (3,425; 3,573; e 3,401 mm), DMG (2,438; 2,682; e 2,541 mm) e IS $(0,77 ; 0,79$; e 0,81), nas três camadas avaliadas. Para o DMP e DMG, não foram verificadas diferenças $(p \leq 0,05)$ entre tratamentos no SPDH; porém, esses índices foram superiores aos do SPC; os de DMP, iguais aos da área de mata; e os de DMG, maiores na camada de 0-5 e 5-10 cm. Na camada de 10-20 cm, no SPDH, o tratamento com nabo-forrageiro apresentou maiores valores de DMP $(4,520 \mathrm{~mm})$, DMG $(4,284 \mathrm{~mm})$ e IS $(1,07)$. Em relação à distribuição dos agregados por classes de diâmetro, o SPC evidenciou, respectivamente, os menores $(14,22 ; 14,75$; e $13,86 \mathrm{~g})$ e maiores $(4,94 ; 3,44 ; \mathrm{e} 3,52 \mathrm{~g} / 3,0 ; 3,0 ; \mathrm{e} 3,76 \mathrm{~g})$ valores para macro e meso/microagregados, enquanto o SPDH demonstrou maiores valores de macroagregados (médias de 19,90; 20,48; e 18,56 g) em comparação à mata $(16,0 ; 16,31 ;$ e $15,47 \mathrm{~g})$ e ao SPC $(14,22 ; 14,75 ;$ e $13,86 \mathrm{~g})$ nas três camadas avaliadas. O uso de plantas de cobertura, solteiras ou consorciadas, em SPD de cebola foi eficiente para recuperar e aumentar os teores de COT e os índices de DMP, DMG e IS em relação ao SPC; e, em comparação à área de mata, aumentou o DMG (0-5 e 5-10 cm). O nabo-forrageiro aumentou a agregação do solo (DMG e IS) na camada de 10-20 cm em relação aos demais tratamentos com plantas de cobertura. A ACP evidenciou a perda de COT e o aumento dos meso e microagregados no SPC, assim como a substituição do SPC por SPDH com plantas de cobertura elevou a formação de macroagregados estáveis em água, com posterior aumento do DMP, DMG e IS.

Palavras-chave: sistema plantio direto de hortaliças, plantas de cobertura, índices de agregação, análise de componentes principais.

\section{ABSTRACT: TOTAL ORGANIC CARBON AND SOIL AGGREGATION UNDER A NO-TILLAGE AGROECOLOGICAL SYSTEM AND CONVENTIONAL TILLAGE SYSTEM FOR ONION}

As a result of soil management systems, like the conventional tillage system (CTS) versus the no-tillage system (NTS) for vegetable crops, modifications in soil properties occur, which change, for example, the rates of soil aggregation and the content of total organic carbon (TOC). The aim of this study was to quantify the TOC contents and evaluate the rates of soil aggregation and the distribution of aggregates by diameter classes in a soil planted to onion in NTS and CTS and compare them to an adjacent forest area in Ituporanga, Santa Catarina, Brazil. We evaluated the following treatments, which consisted of planting cover crops, alone and intercropped, in NTS: spontaneous vegetation (SV); $100 \%$ oats; $100 \%$ rye; $100 \%$ wild radish; intercropping of wild radish (14\%) and rye (86\%); and intercropping of wild radish $(14 \%)$ and oats (86\%). We also evaluated an onion-growing area under CTS for \pm 37 years, and a forest area (secondary forest for \pm 30 years), both adjacent to the experimental area. In September 2013, five years after setting up treatments with cover crops, undisturbed soil samples were collected from the 0-5, 5-10, and 10-20 cm soil layers, and aggregates were separated to assess stability by the wet method. In the aggregates, we quantified TOC and, after separation into diameter classes ( $8.00 \mathrm{~mm}>\emptyset \geq 0.105 \mathrm{~mm})$, we calculated the mean weighted diameter (MWD) and mean geometric diameter (MGD) of the aggregates, the distribution of the aggregates in macroaggregates $(\emptyset \geq 2.0 \mathrm{~mm})$, mesoaggregates $(2.0>\emptyset \geq 0.25 \mathrm{~mm})$, and microaggregates $(\emptyset<0.25 \mathrm{~mm})$, and the aggregate sensitivity index (SI). Data underwent analysis of variance and principal component analysis (PCA). The highest TOC contents were found in the forest area $(52.83,37.77$, and $26.70 \mathrm{~g} \mathrm{~kg} 1$ for the depths of $0-5,5-10$, and 10-20 $\mathrm{cm}$, respectively) and the lowest

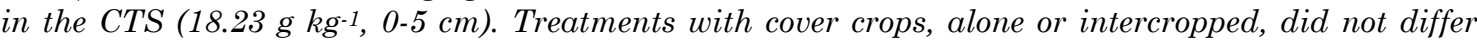
among themselves $(p \leq 0.05)$ for TOC, or in relation to the control area $(S V)$. The CTS had the lowest rates of $M W D(3.425,3.573$, and $3.401 \mathrm{~mm}), M G D(2.438,2.682$, and $2.541 \mathrm{~mm})$ and $S I(0.77,0.79$, and $0.81)$ in the three layers evaluated. For MWD and MGD, differences were not observed ( $p \leq 0.05)$ among treatments in NTS, but these rates were higher than the rates of CTS; the MWD readings were equal to the forest area; and the MGD readings were higher in the 0-5 and 5-10 cm layers. In the 10-20 cm layer, in the NTS, treatment with wild radish showed higher values of MWD (4.520 $\mathrm{mm}), M G D(4.284 \mathrm{~mm})$, and SI (1.07). Regarding the distribution of aggregates by diameter classes, the CTS showed the smallest 
(14.22, 14.75, and $13.86 \mathrm{~g})$ values for macroaggregates, and largest $(4.94,3.44$, and $3.2 \mathrm{~g} / 3.0$, 3.0, and $3.76 \mathrm{~g})$ values for meso-/microaggregates, respectively. The NTS showed higher macroaggregate values (means of 19.90, 20.48, and 18.56 g) compared to the forest area (16.0,16.31, and $15.47 \mathrm{~g})$ and to the CTS (14.22, 14.75, and $13.86 \mathrm{~g})$ in the three layers evaluated. The use of cover crops, alone or intercropped, in NTS of onion was quick in recovering and increasing the TOC and the MWD, MGD, and SI indices in relation to the CTS, and, compared to the forest area, the MGD increased $(0-5$ and $5-10 \mathrm{~cm})$. Oilseed radish increased soil aggregation (MGD and SI) in the 10-20 cm layer compared to the other treatments with cover crops. The PCA showed loss of TOC, and increase in the meso- and microaggregates of CTS, just as the substitution of CTS for NTS with cover plants increased the formation of macroaggregates stable in water, with a subsequent increase in the MWD, MGD, and SI indices.

Keywords: no-tillage system for vegetables, cover crops, aggregation index, principal component analysis.

\section{INTRODUÇÃO}

O Estado de Santa Catarina (SC) é o maior produtor nacional de cebola, apresentando em 2013/2014 rendimento médio de 20 t ha ${ }^{-1}$ e produção média de 413.848 mil toneladas (Acate, 2014). Essa hortaliça tem importância econômica e social para o Estado, em razão do número de empregos e da renda gerada em toda a sua cadeia produtiva (IBGE, 2013).

O cultivo da cebola sob sistema de preparo convencional do solo (SPC) caracteriza-se pelo excessivo revolvimento do solo, sendo na ocasião do plantio realizada aração e, posteriormente, destorroamento com enxada rotativa, o que ocasiona a pulverização do solo e, consequentemente, sua degradação física, química e biológica. A redução dos danos ocasionados pelo mau uso do solo pode ser alcançada utilizando-se o sistema plantio direto (SPD); nesse caso, denominado de SPD de hortaliças (SPDH), onde se tem o preparo do solo restrito à linha de plantio. O SPDH, no caso da cultura da cebola, corresponde àquele em que as mudas são produzidas em canteiros e, em seguida, transplantadas em sulcos preparados por semeadoras adaptadas para o corte da cobertura morta e do solo (Epagri, 2013).

A utilização de plantas de cobertura incrementa a quantidade de fitomassa depositada na superfície do solo, reduz a erosão e aumenta a infiltração de água no solo (Hoorman, 2009; Panachuki et al., 2011; Doneda et al., 2012; Guedes Filho et al., 2013). Essa fitomassa, após sua decomposição, aumenta a atividade microbiana, o acúmulo de nutrientes e matéria orgânica nas camadas superficiais do solo e, consequentemente, favorece o aumento da estabilidade dos agregados do solo (Loss et al., 2011; Casali, 2012; Lima Filho et al., 2014). Foi verificado que o uso de plantas de cobertura em SPD melhora a agregação do solo no longo dos anos de cultivo, em comparação ao SPC (Calegari et al., 2006; Loss et al., 2014), e que o tipo de cultura implantada interfere de forma diferenciada na estabilidade dos agregados (Bronick, Lal, 2005; Liu et al., 2005; Loss et al., 2011).

As espécies de plantas de cobertura da família das gramíneas, que apresentam sistema radicular fasciculado, renovado regularmente, são mais eficientes em aumentar e manter a estabilidade de agregados em relação às leguminosas. Essas, por sua vez, têm sistema radicular pivotante e incrementam o teor de $\mathrm{N}$ do solo (Hermawan e Bomke, 1997; Nascimento et al., 2005; Coutinho et al., 2010). Com o consórcio de plantas que possuem diferentes sistemas radiculares, tem-se um ambiente favorável à formação e manutenção dos agregados do solo, com destaque para a classe dos macroagregados (Loss et al., 2011; Costa Jr et al., 2012; Casali, 2012).

Os macroagregados, por serem estruturas complexas e diversificadas, com grande capacidade para reter energia e matéria adicionada na forma de $\mathrm{C}$, representam bom indicador da qualidade física do solo (Vezzani e Mielniczuk, 2011). Dessa forma, também se tem a melhoria de outras propriedades físicas do solo, como a diminuição dos valores de densidade e aumento da porosidade, aeração e capacidade de retenção e infiltração de água no solo (Hoorman, 2009; Guedes Filho et al., 2013).

Os objetivos deste trabalho foram quantificar os teores de C orgânico total do solo (COT) e avaliar os índices de agregação do solo e a distribuição dos agregados por classes de diâmetro sob cultivo de cebola em SPDH e SPC do solo, comparados a uma área de mata adjacente em Ituporanga, SC.

\section{MATERIAL E MÉTODOS}

O experimento foi conduzido na Estação Experimental da Empresa de Pesquisa Agropecuária e Extensão Rural de Santa Catarina (Epagri), município de Ituporanga, Santa Catarina (S $27^{\circ} 24^{\prime} 52^{\prime \prime}$ e W $49^{\circ} 36^{\prime}$ 9", $475 \mathrm{~m}$ de altitude). O clima da região, segundo a classificação de Köppen, é subtropical mesotérmico úmido ( $\mathrm{Cfa}$ ), com temperatura média anual de $17,6^{\circ} \mathrm{C}$ e precipitação pluvial anual média de $1.400 \mathrm{~mm}$ (Souza et al., 2013). O solo foi classificado como Cambissolo Húmico (Embrapa, 2006). 
O experimento foi instalado em uma área com histórico de cultivo de cebola por meio do SPC (aração e enxada rotativa) por 20 anos até 1996. A partir desse ano, foi aplicado calcário na superfície do solo, com posterior incorporação, para elevar o $\mathrm{pH}$ em água até 6,0 . Em seguida, foi implantado o sistema de cultivo mínimo de cebola com rotação de culturas e plantas de cobertura (aveia - Avena strigosa, mucuna - Mucuna aterrima, milheto - Pennisetum glaucum, crotalaria - Crotalaria juncea, ervilhaca - Vicia sativa), sistema que permaneceu de 1996 a 2007. Posteriormente, foi implantada a cultura da batata-doce, explorada até 2009. A partir de então, instalou-se o experimento com o SPDH de cebola.

No momento da implantação do experimento (2009), o solo da camada de 0-10 $\mathrm{cm}$ apresentava: $380 \mathrm{~g} \mathrm{~kg}^{-1}$ de argila; $23,2 \mathrm{~g} \mathrm{~kg}^{-1}$ de C orgânico total; $\mathrm{pH}$ em água igual a 6,$0 ;$ índice SMP 6,2; $\mathrm{P} 26,6 \mathrm{mg} \mathrm{dm}^{-3} \mathrm{e} \mathrm{K}$ $145,2 \mathrm{mg} \mathrm{dm}^{-3}$ (extrator Mehlich-1); $\mathrm{Al}^{3+} 0,0 \mathrm{cmol}_{\mathrm{c}} \mathrm{kg}^{-1}$; $\mathrm{Ca}^{2+} 7,2 \mathrm{cmol}_{\mathrm{c}} \mathrm{kg}^{-1} ; \mathrm{e} \mathrm{Mg}^{2+} 3,4 \mathrm{cmol}_{\mathrm{c}} \mathrm{kg}^{-1}$ (extrator KCl $1 \mathrm{~mol} \mathrm{~L}^{-1}$ ) (Tedesco et al., 1995). No mesmo ano, no momento da instalação do experimento, a vegetação espontânea foi dessecada, usando-se o herbicida glifosato. A partir de então, não foram mais utilizadas aplicações de agrotóxicos.

Os tratamentos constituíram-se do plantio de plantas de cobertura solteiras e consorciadas, sendo: testemunha com vegetação espontânea (VE), composta de 20 famílias botânicas, com predomínio de seis famílias (85\%), conforme Vilanova (2010): Amaranthaceae (10\%), Asteraceae, Caryophyllaceae, Compositae (10\%), Convolvulaceae, Cruciferae, Cyperaceae (25\%), Euphorbiaceae, Fabaceae, Lamiaceae (10 \%), Leguminosae, Liliaceae, Malvaceae, Oxalidaceae (10\%), Plantaginaceae, Poaceae, Polygonaceae (20\%), Portulacaceae, Rubiaeceae, Solanaceae; $100 \%$ aveia (Avena strigosa Schreb.), com densidade de semeadura (DS) de $120 \mathrm{~kg} \mathrm{ha}^{-1}$; $100 \%$ centeio (Secale cereale L.), com DS de $120 \mathrm{~kg} \mathrm{ha}^{-1} ; 100 \%$ nabo-forrageiro (Raphanus sativus L.), com DS de $20 \mathrm{~kg} \mathrm{ha}^{-1}$; consórcio de nabo-forrageiro (14\%) e centeio (86 \%), com DS de 60 e $10 \mathrm{~kg} \mathrm{ha}^{-1}$, respectivamente; consórcio de nabo-forrageiro (14\%) e aveia (86\%), com DS de 10 e $60 \mathrm{~kg} \mathrm{ha}^{-1}$, respectivamente. Em abril de 2010 , a aveia-preta foi substituída por cevada (Hordeum vulgare L.); a partir de abril de 2011, a cevada foi novamente substituída pela aveia-preta, em razão da dificuldade em adquirir as sementes dessa cultura. As espécies de inverno foram semeadas a lanço em abril de cada ano e, em seguida, uma máquina semeadora de cereais foi passada duas vezes na área. As quantidades de sementes por hectare foram calculadas com base na recomendação de Monegat (1991), sendo acrescidos de $50 \%$ sobre a quantidade calculada. Os tratamentos foram casualizados em blocos, com cinco repetições. Cada unidade experimental tinha $25 \mathrm{~m}^{2}(5 \times 5 \mathrm{~m})$. Em julho de 2009, 2010, 2011, 2012 e 2013, todas as espécies de inverno foram acamadas, por meio de um rolo-faca (modelo RF240, MBO Ltda).

Adicionalmente, foram avaliados mais dois tratamentos, ambos adjacentes ao experimento, sendo a área original de cultivo de cebola mantida sob SPC por 20 anos até 1996. Somando-se os anos subsequentes, de 1996 a 2013, época de coleta das amostras de solo, foram totalizados 37 anos em SPC. O outro tratamento adicional, uma floresta secundária com \pm 30 anos, representou a condição natural do solo. No SPC, a partir do ano de 2007, a cebola foi cultivada em sucessão com milheto, no verão. $\mathrm{O}$ milheto foi acamado na floração com rolo-faca e, após 30-60 dias, realizada aração seguida de gradagem para implantar a cultura da cebola. A adubação foi realizada conforme a CQFSSC/RS (2004).

Após o acamamento das plantas de cobertura de inverno, no mês de julho de cada ano, foram aplicados na área $96 \mathrm{~kg} \mathrm{ha}^{-1} \mathrm{de}_{2} \mathrm{O}_{5}$, na forma de fosfato natural de Gafsa moído, $175 \mathrm{~kg} \mathrm{ha}^{-1}$ de $\mathrm{P}_{2} \mathrm{O}_{5}, 125 \mathrm{~kg} \mathrm{ha}^{-1}$ de $\mathrm{K}_{2} \mathrm{O}$ e $160 \mathrm{~kg} \mathrm{ha}^{-1}$ de $\mathrm{N}$, na forma de dejetos de aves, sendo metade aplicada no plantio das mudas de cebola e o restante 30 dias após o plantio. A partir da safra de 2011, não foi aplicado fosfato natural, pois os teores foram interpretados como muito altos, conforme a CQFSSC/RS (2004). Em seguida, foram abertos sulcos usando uma máquina de plantio direto adaptada, e foram transplantadas manualmente as mudas de cebola cv. 'Empasc 352' - Bola Precoce. $\mathrm{O}$ espaçamento usado foi de $0,50 \mathrm{~m}$ entrelinhas e $0,10 \mathrm{~m}$ entre plantas, com 10 linhas de cebola por parcela. Foram realizadas capinas aos 60 e 90 dias após o plantio das mudas de cebola. Após a colheita da cebola, em dezembro de cada ano, sempre foi realizado o plantio da mucuna-preta (Mucuna aterrima Piper e Tracy) no verão em toda a área cultivada. A mucuna é acamada no mês de março de cada ano para no mês seguinte (abril) fazer a semeadura das plantas de cobertura de inverno.

Os valores médios de produção de matéria seca e da cebola nas áreas avaliadas referentes a 2013, ano da coleta das amostras de solo, são observados no quadro 1.

Em setembro de 2013, após cinco anos de implantação dos tratamentos, realizou-se a coleta de solo para determinar o carbono orgânico total do solo (COT) e a estabilidade dos agregados. Foi realizada a abertura de uma minitrincheira de $40 \times 40 \times 40 \mathrm{~cm}$ em cada parcela, onde foram coletadas amostras indeformadas de solo nas camadas de 0-5, 5-10 e 10-20 cm, utilizando-se uma pá de corte. As amostras foram devidamente acondicionadas em sacos plásticos e encaminhadas ao Laboratório de Manejo e Classificação de Solos da Universidade Federal de Santa Catarina (UFSC). As amostras foram secas ao ar e, em seguida, destorroadas manualmente, seguindo fendas ou pontos de fraqueza, e passadas em um conjunto de peneiras de malha 8,00 e $4,00 \mathrm{~mm}$ para obter os agregados do solo, conforme Embrapa (1997). 
Quadro 1. Produção de matéria seca das plantas de cobertura de inverno e da mucuna no verão e produção de cebola referente à safra agrícola de 2012/2013 em sistema de uso do solo

\begin{tabular}{lccc}
\hline \multirow{2}{*}{ Sistema de uso } & \multicolumn{2}{c}{ Matéria seca } & $\begin{array}{c}\text { Produção } \\
\text { de cebola }\end{array}$ \\
\cline { 2 - 3 } & Inverno & Verão & Mg ha $^{-1}$ \\
Vegetação espontânea & \multicolumn{2}{c}{$\mathrm{kg} \mathrm{ha}^{-1}$} & \\
\cline { 2 - 3 } Aveia & 5.480 & 2.275 & 16,74 \\
Centeio & 5.220 & 1.951 & 19,94 \\
Nabo-forrageiro & 4.635 & 2.286 & 18,93 \\
Aveia + nabo & 5.203 & 2.155 & 18,68 \\
Centeio + nabo & 4.656 & 2.283 & 18,58 \\
SPC & - & 12.000 & 18,08 \\
\hline
\end{tabular}

(1) $\mathrm{O}$ rendimento da cebola é muito superior no SPC, principalmente em razão do controle químico do míldio, doença fúngica que pode promover perdas superiores a $70 \%$ no rendimento de cebola. No sistema orgânico (SPDH), ainda não se dispõe de tecnologias para reduzir o efeito dessa doença.

Dos agregados retidos na peneira de $4,00 \mathrm{~mm}$, pesaram-se $25 \mathrm{~g}$, que foram transferidos para uma peneira de $2,00 \mathrm{~mm}$, que compõe um conjunto de peneiras com diâmetro de malha decrescente, a saber: 2,$00 ; 1,00 ; 0,50 ; 0,25$; e $0,105 \mathrm{~mm}$, conforme Embrapa (1997). Os agregados inicialmente colocados na peneira de $2,00 \mathrm{~mm}$ foram umedecidos com borrifador de água e, posteriormente, o conjunto de peneiras foi submetido à tamisação vertical via úmida por 15 min no aparelho de Yoder (Yoder, 1936). Transcorrido esse tempo, o material retido em cada peneira foi retirado, separado com jato d'água, colocado em placas de Petri previamente pesadas e identificadas e levado à estufa a $105{ }^{\circ} \mathrm{C}$ até obter massa seca constante.

A partir da massa de agregados, foram calculados: o diâmetro médio geométrico (DMG) e o diâmetro médio ponderado (DMP) dos agregados, segundo a Embrapa (1997). O índice de sensibilidade (Bolinder et al., 1999) foi calculado pela expressão: $\mathrm{IS}=\mathrm{DMGt} / \mathrm{DMGo}$ ou DMPt/DMPo, em que IS: índice de sensibilidade; DMGt ou DMPt: valor do DMG/DMP do solo em cada tratamento; e DMGo ou DMPo: valor do DMG ou DMP do solo na cobertura original (mata secundária). A partir da massa dos agregados, foi avaliada ainda a sua distribuição nas seguintes classes de diâmetro médio, conforme Costa Jr. et al. (2012): $\emptyset \geq 2,0 \mathrm{~mm}$ (macroagregados); $2,0>\emptyset \geq 0,25 \mathrm{~mm}$ (mesoagregados); e $\varnothing<0,25 \mathrm{~mm}$ (microagregados).

Para quantificar oCOT, nas mesmas profundidades, foram coletadas amostras deformadas de solo. Essas foram secas ao ar e tamisadas em malha de $2,00 \mathrm{~mm}$ (Embrapa, 1997). Nesse material, determinou-se o COT segundo Yeomans e Bremner (1988).

Os resultados foram analisados quanto à normalidade e homogeneidade dos dados por meio dos testes de Lilliefors e Cochran, respectivamente e, posteriormente, analisados seguindo o delineamento em blocos casualizados, com oito tratamentos (vegetação espontânea, aveia, centeio, nabo, nabo + centeio, nabo + aveia, SPC e mata) e cinco repetições. Os resultados foram submetidos à análise de variância pelo teste $\mathrm{F}$, e os valores médios, quando significativos, comparados pelo teste de Skott-Knott a $5 \%$. Também foi realizada uma análise estatística multivariada (análise de componentes principais - ACP) com todos os dados obtidos. A ACP é utilizada para reduzir as dimensões dos dados e, consequentemente, facilitar a análise por meio do gráfico do círculo de correlações (Herlihy e McCarthy, 2006).

\section{RESULTADOS E DISCUSSÃO}

Os maiores teores de COT foram observados na área de mata nas três profundidades avaliadas. Não foram verificadas diferenças entre os tratamentos com plantas de coberturas solteiras e consorciadas nas profundidades avaliadas, enquanto a área de SPC apresentou os menores teores de COT na camada superficial do solo e valores iguais aos verificados àqueles das plantas de cobertura nas profundidades de 5-10 e 10-20 cm (Quadro 2).

Os maiores valores de COT na área de mata estão relacionados ao constante aporte e acúmulo de resíduos vegetais (folhas, galhos e raízes, por exemplo), associados à sua qualidade (serapilheira mais lignificada), o que mantém o estado estável nas adições e perdas de COT (Urquiaga et al., 2005; Loss et al., 2012; Bezerra et al., 2013).

Quadro 2. Teores médios de carbono orgânico total (COT) do solo em sistemas de uso do solo com cultivo de cebola, nas profundidades de $0-5$, $5-0$ e $10-20 \mathrm{~cm}$

\begin{tabular}{lccc}
\hline \multirow{2}{*}{ Sistema de uso } & \multicolumn{3}{c}{ COT } \\
\cline { 2 - 4 } & $\mathbf{0 - 5} \mathbf{~ c m}$ & $\mathbf{5 - 1 0} \mathbf{~ c m}$ & $\mathbf{1 0 - 2 0} \mathbf{~ c m}$ \\
\hline \multirow{2}{*}{ Vegetação espontânea } \\
Aveia & $31,23 \mathrm{~b}$ & $20,20 \mathrm{~b}$ & $17,47 \mathrm{~b}$ \\
Centeio & $30,17 \mathrm{~b}$ & $20,93 \mathrm{~b}$ & $19,47 \mathrm{~b}$ \\
Nabo & $26,30 \mathrm{~b}$ & $18,20 \mathrm{~b}$ & $16,70 \mathrm{~b}$ \\
Aveia + nabo & $28,50 \mathrm{~b}$ & $20,53 \mathrm{~b}$ & $16,80 \mathrm{~b}$ \\
Centeio + nabo & $32,60 \mathrm{~b}$ & $19,53 \mathrm{~b}$ & $17,97 \mathrm{~b}$ \\
SPC & $33,63 \mathrm{~b}$ & $20,13 \mathrm{~b}$ & $16,97 \mathrm{~b}$ \\
Mata & $18,23 \mathrm{c}$ & $20,23 \mathrm{~b}$ & $19,20 \mathrm{~b}$ \\
CV (\%) & $52,83 \mathrm{a}$ & $37,77 \mathrm{a}$ & $26,70 \mathrm{a}$ \\
\hline
\end{tabular}

Médias seguidas de mesma letra na coluna não diferem entre si pelo teste de Scott-Knott a $5 \%$. CV: coeficiente de variação. 
Já no SPC, as práticas de revolvimento do solo (aração e enxada rotativa) resultam em alta perturbação do solo, causando efeitos negativos como a ruptura dos agregados do solo, com exposição da matéria orgânica antes protegida fisicamente no interior dos agregados, proporcionando menores teores de COT na camada superficial do solo. Resultados semelhantes foram verificados por Rosa et al. (2011) ao avaliarem os teores de COT em solos de textura argilosa no sul do Brasil em SPD e SPC. Os autores observaram que o SPC promoveu perdas de COT, principalmente na camada superficial do solo $(0-5 \mathrm{~cm})$, mas não verificaram diferenças entre o SPC e SPD nas camadas subsuperficiais. Esse resultado também foi verificado neste estudo para o SPC e SPDH (Quadro 2), que decorre do fato de que no SPC tem-se a incorporação dos resíduos vegetais depositados na superfície do solo em camadas mais profundas, enquanto no SPDH, com as plantas de cobertura, tem-se, além da manutenção da fitomassa na superfície do solo, a incorporação biológica de $\mathrm{C}$ via sistema radicular em profundidade. Madari et al. (2005), Boddey et al. (2010) e Llerme et al. (2013) observaram resultados similares em solos manejados com SPD e SPC.

No SPDH, apesar da ausência de diferenças entre os sistemas avaliados na camada superficial do solo, verificou-se que o consórcio de centeio + nabo apresentou 28 e $18 \%$ a mais de COT em relação às plantas solteiras de centeio e nabo, respectivamente (Quadro 2). Para o consórcio aveia + nabo, também se observaram maiores proporções de COT, 14 e $8 \%$, em relação às plantas solteiras de nabo e aveia, respectivamente (Quadro 2).

Essas maiores proporções de COT podem estar associadas à relação $\mathrm{C} / \mathrm{N}$ dos consórcios. De acordo com Giacomini et al. (2003), o consórcio entre diferentes espécies proporciona a produção de uma fitomassa, cuja relação $\mathrm{C} / \mathrm{N}$ é intermediária àquela das espécies em cultura pura. Por meio dessa estratégia de cultivo das plantas de cobertura, Doneda et al. (2012) verificaram que o consórcio de centeio + nabo e aveia + nabo apresentaram menor velocidade de decomposição dos resíduos culturais em relação aos cultivos solteiros, assim como a relação $\mathrm{C} / \mathrm{N}$ intermediária da fitomassa. Assim, pode-se alterar a taxa de decomposição dos resíduos culturais de modo a proporcionar, simultaneamente, cobertura mais eficiente e duradoura do solo e melhor sincronia entre o fornecimento e a demanda de nutrientes pelas culturas em sucessão, principalmente o $\mathrm{N}$ (ASHS, 2010).

É importante ressaltar que incrementos de $\mathrm{N}$, seja por fixação biológica (leguminosas) ou adubação nitrogenada, favorecem o acúmulo de COT, pois não ocorre aumento de COT no solo se a quantidade de $\mathrm{N}$ for limitante à produtividade biológica (Urquiaga et al., 2005). Essa estreita relação entre os teores de $\mathrm{C}$ e $\mathrm{N}$ foi observada em áreas localizadas em diferentes regiões do Brasil, em cultivo de grãos e condições de vegetação nativa (Sisti et al., 2004; Loss et al., 2012), corroborando os resultados encontrados neste estudo.

No longo dos cinco anos de duração do experimento, cada tratamento adicionou ao solo diferentes quantidades de resíduos vegetais (Quadro 1). Associado a esse fato, em SPD, os resíduos vegetais permanecem na superfície do solo, diminuindo a sua mineralização (Gatiboni et al., 2007), acarretando em maior acúmulo de COT na camada de 0-5 cm (Quadro 2). Além da ausência de revolvimento do solo decorrente da adoção do SPD, a manutenção de um considerável aporte de resíduos vegetais na superfície do solo, somada ao contínuo crescimento radicular propiciado pelo cultivo de plantas de cobertura, redunda em melhoria e manutenção de boa agregação do solo (Gracia e Rosolem, 2010; Loss et al., 2011; Vezzani e Mielniczuk, 2011).

Em relação aos índices de agregação, DMP e DMG, os menores valores foram observados no SPC em todas as profundidades avaliadas (Quadro 3). Esse resultado é decorrente da ruptura dos agregados do solo por meio das operações de preparo, o que acelerou a decomposição da matéria orgânica e promoveu os menores teores de COT (Quadro 2) e principalmente a diminuição da matéria orgânica particulada (MOP), que pode formar pontes de nucleação contribuindo para a formação de microagregados no interior de macroagregados (Golchin et al., 1994). Com a exposição da MOP, que estava protegida fisicamente no interior dos agregados, tem-se sua rápida decomposição, com posterior decréscimo da atividade microbiana e da liberação de mucilagens, acarretando a perda de estabilidade dos macroagregados e, consequentemente, aumento dos microagregados (Oades, 1984) e redução dos índices DMP e DMG.

Esses resultados são semelhantes aos observados por Loss et al. (2014), que encontraram menores valores de DMP, DMG, MOP e C mineralizável em áreas em SPC, quando comparadas com áreas em SPD, pastagem e floresta secundária no sul do Brasil.

O DMP não diferiu entre os tratamentos com plantas de coberturas e a área de mata, nas camadas de $0-5$ e $5-10 \mathrm{~cm}$. Porém, o tratamento com cultivo de nabo-forrageiro apresentou maior valor de DMP na camada de $10-20 \mathrm{~cm}$. Para o DMG, também não foram observadas diferenças entre tratamentos com plantas de coberturas nas camadas de 0-5 e 5-10 cm; somente ocorreu diferença na profundidade de $10-20 \mathrm{~cm}$, onde o nabo-forrageiro evidenciou o maior valor. Quanto aos tratamentos com plantas de cobertura, esses demonstraram maiores valores de DMG em relação à área de mata, nas camadas de $0-5$ e $5-10 \mathrm{~cm}$ (Quadro 3). 
Quadro 3. Diâmetro médio ponderado (DMP) e diâmetro médio geométrico (DMG) de agregados em sistemas de uso do solo com cultivo de cebola, nas profundidades de 0-5, 5-0 e 10-20 cm

\begin{tabular}{|c|c|c|c|c|c|c|}
\hline \multirow{2}{*}{ Sistema de uso } & \multicolumn{3}{|c|}{ DMP } & \multicolumn{3}{|c|}{ DMG } \\
\hline & $0-5 \mathrm{~cm}$ & $5-10 \mathrm{~cm}$ & $10-20 \mathrm{~cm}$ & $0-5 \mathrm{~cm}$ & $5-10 \mathrm{~cm}$ & $10-20 \mathrm{~cm}$ \\
\hline & \multicolumn{6}{|c|}{$\mathrm{mm}$} \\
\hline Vegetação espontânea & $4,701 \mathrm{a}$ & $4,698 \mathrm{a}$ & $4,121 \mathrm{~b}$ & $4,437 \mathrm{a}$ & $4,413 \mathrm{a}$ & $3,459 \mathrm{~b}$ \\
\hline Aveia & $4,615 \mathrm{a}$ & $4,661 \mathrm{a}$ & $4,372 \mathrm{~b}$ & $4,444 \mathrm{a}$ & $4,489 \mathrm{a}$ & $3,793 \mathrm{~b}$ \\
\hline Centeio & $4,677 \mathrm{a}$ & $4,651 \mathrm{a}$ & $4,322 \mathrm{~b}$ & $4,496 \mathrm{a}$ & $4,361 \mathrm{a}$ & $3,876 \mathrm{~b}$ \\
\hline Nabo & $4,460 \mathrm{a}$ & $4,650 \mathrm{a}$ & $4,520 \mathrm{a}$ & $4,272 \mathrm{a}$ & $4,413 \mathrm{a}$ & $4,284 \mathrm{a}$ \\
\hline Aveia + nabo & $4,420 \mathrm{a}$ & $4,645 \mathrm{a}$ & $4,200 \mathrm{~b}$ & $4,142 \mathrm{a}$ & $4,368 \mathrm{a}$ & $3,530 \mathrm{~b}$ \\
\hline Centeio + nabo & $4,657 \mathrm{a}$ & $4,612 \mathrm{a}$ & $4,238 \mathrm{~b}$ & $4,395 \mathrm{a}$ & 4,406 a & $3,672 \mathrm{~b}$ \\
\hline $\mathrm{SPC}$ & $3,425 \mathrm{~b}$ & $3,573 \mathrm{~b}$ & $3,401 \mathrm{c}$ & $2,438 \mathrm{c}$ & $2,682 \mathrm{c}$ & $2,541 \mathrm{c}$ \\
\hline Mata & $4,409 \mathrm{a}$ & $4,511 \mathrm{a}$ & $4,256 \mathrm{~b}$ & $3,908 \mathrm{~b}$ & $4,044 \mathrm{~b}$ & $3,607 \mathrm{~b}$ \\
\hline CV (\%) & 5,35 & 3,81 & 5,57 & 4,37 & 4,79 & 8,97 \\
\hline
\end{tabular}

Médias seguidas de mesma letra na coluna não diferem entre si pelo teste de Scott-Knott a 5 \%. CV: coeficiente de variação.

A similaridade dos valores de DMP, assim como os maiores valores de DMG, nos tratamentos com plantas de cobertura, solteiras e consorciadas, e mesmo com a vegetação espontânea em relação à área de mata, indicam que o SPDH com uso de plantas de cobertura é eficiente para melhorar e aumentar a agregação do solo em área que foi manejada com SPC. Esse aumento é decorrente, tanto de processos físicos associados à exploração do solo pelas raízes, que durante o processo de crescimento exercem pressão sobre as partículas minerais e promovem a sua aproximação (Gracia e Rosolem, 2010; Casali, 2012; Guedes Filho et al., 2013), como químicos, associados a exsudação de compostos que apresentam efeito aglutinador dos constituintes sólidos do solo (Liu et al., 2005; Vezzani e Mielniczuk, 2011; Casali, 2012).

Os maiores valores de DMP e DMG no tratamento com o nabo-forrageiro na profundidade de $10-20 \mathrm{~cm}$ (Quadro 3) podem ser em razão do sistema radicular pivotante e agressivo dessa crucífera que, à medida que se desenvolve, pressiona as partículas de solo ao seu redor, favorecendo a formação de agregados maiores e mais resistentes (Casali, 2012; Guedes Filho et al., 2013). Angers e Caron (1998) relataram que o cultivo do solo com plantas com sistema radicular vigoroso, a exemplo do nabo-forrageiro, promove a compressão lateral do solo, que somada à ação de microrganismos que atuam na decomposição das mucilagens produzidas pelo sistema radicular favorece a agregação. Segundo Six et al. (2004), o crescimento radicular, associado à distribuição dos exsudatos no solo, estimula a atividade microbiana, cujos subprodutos atuam na formação e estabilização dos agregados. Assim, têm-se os efeitos físico, químico e biológico atuando conjuntamente na formação dos agregados e no aumento dos índices DMP e DMG.

Os maiores valores de DMG para o SPDH a 0-5 e 5-10 cm em relação ao SPC e à área de mata
(Quadro 3) podem ser decorrentes da exsudação de polissacarídeos pelas plantas de cobertura. Segundo Liu et al. (2005), os polissacarídeos exsudados de plantas de cobertura de inverno não leguminosas (azevém, centeio e cevada) têm, em um curto espaço de tempo, alto efeito aglutinador das partículas do solo em solos que foram submetidos a sistemas de cultivo intensivos durante longos períodos, como o SPC.

Em relação à distribuição da massa dos agregados estáveis em água, o SPC apresentou, em todas as camadas avaliadas, os menores valores para os macroagregados, enquanto o SPDH os maiores valores, sendo verificados valores intermediários para a área de mata (Figura 1).

Esses resultados indicam que no SPDH, além do efeito da manutenção da fitomassa sobre o solo, tem-se a ação constante do sistema radicular, o que favorece a aproximação das partículas e a liberação de exsudatos, que propiciam a formação de agregados de maior tamanho e maior estabilidade (Six et al., 2004; Panachuki et al, 2011), em comparação ao SPC.

No SPDH, o aumento da macroagregação também pode estar associado ao cultivo de mucuna no verão, em todos os tratamentos, pois por ser uma espécie leguminosa que produz grande quantidade de matéria seca, essa contribui com a incorporação de $\mathrm{C}$ e nutrientes ao solo. Além disso, as leguminosas fazem associações com bactérias e conseguem fixar o $\mathrm{N}$ atmosférico, melhorando a nutrição das plantas e, portanto, promovem o crescimento de microrganismos no solo, que podem influenciar no incremento da estabilidade dos macroagregados (Perin et al., 2002) no SPDH, em comparação à área de SPC e principalmente à área de mata.

Os maiores valores de macroagregados no SPDH evidenciam a capacidade desse sistema em manter e, ou, aumentar a agregação do solo, principalmente por meio do efeito do crescimento das raízes no processo 
(a)

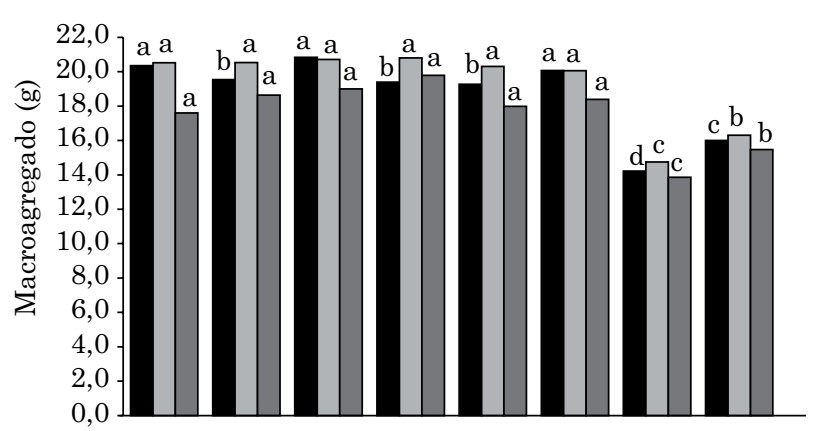

(b)

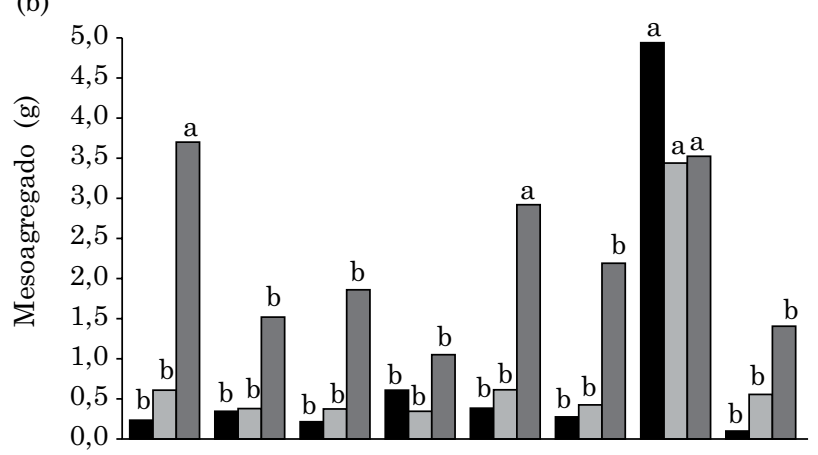

(c)

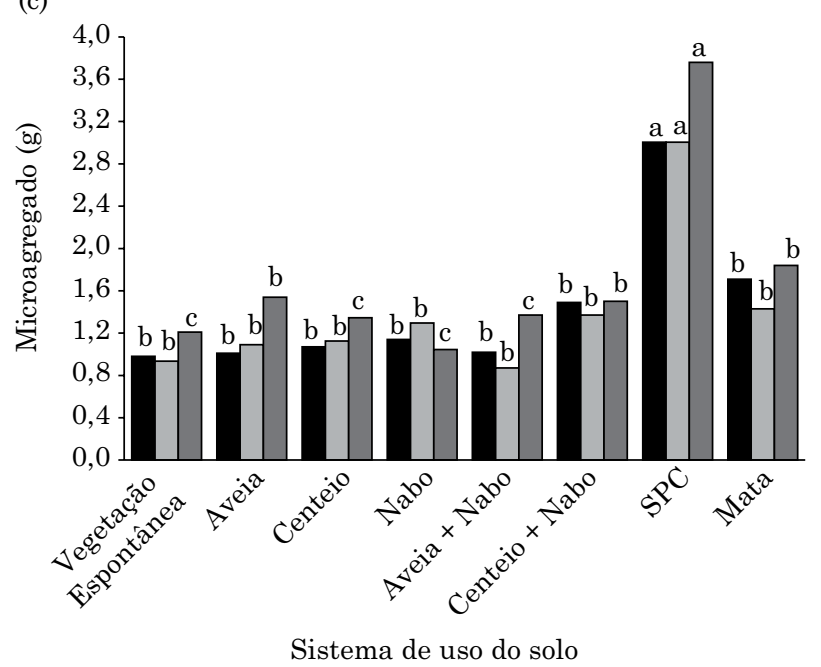

Figura 1. Distribuição da massa de macroagregados $(\emptyset \geq 2,0 \mathrm{~mm})$, mesoagregados $(2,0>\emptyset \geq 0,25 \mathrm{~mm})$ e microagregados $(\varnothing<0,25 \mathrm{~mm})$ estáveis em água em sistemas de uso do solo com cultivo de cebola nas profundidades de 0-5, 5-0 e 10-20 cm. Médias de cinco repetições seguidas de mesma letra, entre sistemas de uso do solo para cada profundidade, não diferem entre si pelo teste de Skott-knott $(p \leq 0,05)$.

de agregação, que estimula a atividade microbiana e, consequentemente, aumenta a quantidade de exsudatos que atuam como agentes de agregação do solo. Ademais, as forças mecânicas que estabilizam agregados ocorrem com maior intensidade com o uso de plantas de cobertura em comparação às culturas comerciais como a soja e o milho (Denef e Six, 2005; Salton et al., 2008; Casali, 2012; Costa Jr et al., 2012).

Entre os tratamentos com plantas de cobertura, verificaram-se diferenças apenas na camada de $0-5 \mathrm{~cm}$, onde o centeio, o centeio + nabo e a vegetação espontânea apresentaram os maiores valores de macroagregados (Figura 1). Além dos efeitos já mencionados, algumas plantas podem favorecer ainda mais a formação de agregados como o consórcio do centeio com o nabo-forrageiro. $\mathrm{O}$ primeiro, por aspectos químicos decorrente do sistema radicular fasciculado e denso, distribui melhor os exsudatos radiculares; e o segundo promove um efeito físico de compressão do solo à medida que desenvolve o seu sistema radicular pivotante (Casali, 2012). Na área testemunha, a diversidade que compõe a vegetação espontânea (20 famílias) também favorece os processos físicos e químicos relacionados à agregação do solo, além dos benefícios oriundos do SPD.

A ausência de diferenças entre os tratamentos com plantas de cobertura solteiras e consorciadas e a área de vegetação espontânea para macroagregados nas camadas de 5-10 e 10-20 cm (Figura 1) indica que o SPD, com o uso de plantas de cobertura, proporciona adequada cobertura vegetal do solo, o que impede a ação direta das gotas de chuva sobre o solo e mantém mais uniforme a umidade e temperatura do solo (Panachuki et al., 2011); por consequência, propicia condições ideais para a atividade biológica que atuará direta e indiretamente na formação dos macroagregados.

Para os meso e microagregados, a área de SPC apresentou os maiores valores em todas as camadas avaliadas (Figura 1). Esse padrão é decorrente da quebra dos macroagregados pela ação dos implementos, que diminuem a estabilidade dos macroagregados, tornando-os mais suscetíveis às forças de ruptura quando separados por via úmida (Mendes et al., 2003; Costa Jr. et al., 2012; Loss et al., 2014). Os menores índices de DMP e DMG (Quadro 3) corroboram os maiores valores de meso e microagregados no SPC.

Entre o SPDH e a área de mata, de maneira geral, verificaram-se valores de meso e microagregados semelhantes em todas as camadas avaliadas, exceto para 10-20 $\mathrm{cm}$. Isso é decorrente do constante aporte de resíduos vegetais sobre o solo e da atuação dos diferentes sistemas radiculares. Além desses fatores, soma-se a ausência de revolvimento do solo, que potencializa a presença e a diversidade de organismos nele, assim promovendo eficiente ciclagem de nutrientes e agregação dele, formando meso e microagregados estáveis em água, que serão unidos, principalmente por matéria orgânica particulada, para formar e estabilizar os macroagregados (Figura 1). 
As maiores quantidades de macroagregados estáveis em água nas áreas em SPDH também podem estar relacionadas à glomalina produzida por fungos micorrízicos. As plantas de cobertura associadas ao SPD aumentam a atividade dos fungos micorrízicos, promovendo eficiente relação simbiótica, onde as plantas fornecem os polissacarídeos, via exsudatos, e os fungos micorrízicos, a proteína para formar uma glicoproteína chamada glomalina, que aumenta a formação de macroagregados (Rilling e Mummey, 2006; Hoorman, 2009).

Partindo do pressuposto de que o estado de agregação máxima ocorre em solos sob vegetaçãonativa (Six et al., 2002), verificou-se que o SPC apresentou a maior quantidade de meso e microagregados e, consequentemente, menores valores de DMP e DMG, em razão da ruptura dos macroagregados (Figura 1; Quadro 3). Comportamento contrário foi observado nos tratamentos com plantas de cobertura solteiras ou consorciadas, onde têm-se os valores de DMP iguais aos da área de mata e valores de DMG maiores que os da área de mata (Quadro 3). Isso promoveu maiores valores de macroagregados no SPDH, em comparação à área de mata (Figura 1).

Em relação ao índice de sensibilidade (IS), verificaram-se valores de DMP e DMG, nos tratamentos com usos agrícolas do solo, diferentes daqueles observados no solo da área de mata. Os valores acima da unidade (área de mata $=1,0$ ), encontrados na maioria dos tratamentos e profundidades do SPDH com plantas de cobertura, representam incremento na agregação, e valores menores que a unidade, redução na agregação (Bolinder at al., 1999; Portugal et al., 2010). Este último caso ocorreu para a área sob SPC, que apresentou ISDMP e ISDMG, em média, $23 \%$ $(0-5 \mathrm{~cm})$ e $20 \%(5-10$ e $10-20 \mathrm{~cm})$ menores que a unidade (Figura 2).

Esses resultados corroboram com os baixos índices de DMP e DMG verificados na área de SPC em relação à área de mata (Quadro 3), somados às menores quantidades de macroagregados estáveis em água (Figura 1), pois as práticas de aração e gradagem desagregaram o solo, culminando em quantidades maiores de agregados de menor tamanho (Figura 1). Loss et al. (2008) avaliaram a agregação do solo e o índice de sensibilidade em diferentes sistemas de uso, em comparação com uma área de floresta secundária e encontraram resultados semelhantes ao deste estudo, em que a área com preparo convencional do solo apresentou o menor valor de IS, sendo esse decorrente das práticas de aração e gradagem.

Por meio dos valores de ISDMP e ISDMG verificados nas áreas em SPDH, pode-se inferir que o uso de plantas de cobertura solteiras e, ou, consorciadas, após cinco anos de implantação em área com \pm 37 anos de histórico de cultivo convencional do solo (SPC), aumentou a agregação

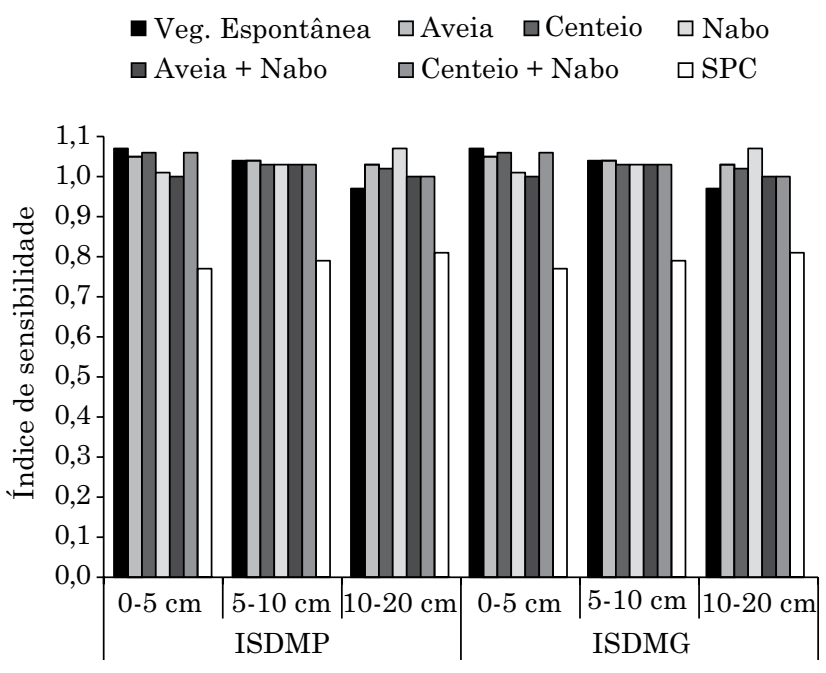

Figura 2. Índice de sensibilidade para diâmetro médio ponderado (ISDMP) e diâmetro médio geométrico (ISDMG) de agregados em sistemas de uso do solo com cultivo de cebola, em relação à mata, nas profundidades de 0-5, 5-0 e 10-20 cm.

do solo, com ênfase para os macroagregados (Figura 1). Somado a isso, verificaram-se ISDMP e ISDMG iguais à unidade para os tratamentos com nabo e centeio + nabo $(0-5 \mathrm{~cm})$ e aveia + nabo e centeio + nabo (10-20 cm), assim como valores superiores à unidade para os demais tratamentos (Figura 2). Merece destaque o nabo-forrageiro na camada de 10-20 cm, que apresentou IS ligeiramente superior à unidade $(7 \%$ superior) e à área testemunha, com vegetação espontânea, que apresentou IS $3 \%$ inferior à unidade (Figura 2). Os maiores valores de IS para o nabo-forrageiro na camada de 10-20 cm corroboram os maiores índices de DMP e DMG (Quadro 3), indicando a eficiência dessa crucífera em aumentar a agregação do solo em áreas com histórico de SPC por longo tempo.

Em relação à análise multivariada, os atributos avaliados foram agrupados em cinco fatores principais, e o ajuste do modelo foi capaz de explicar 95,26 \% das variâncias (Quadro 4). O primeiro componente explicou $61,91 \%$ da variabilidade dos atributos do solo da área experimental. Esse componente é constituído pelos atributos físicos do solo, com destaque para ISDMP, MACRO e DMP (nas três camadas avaliadas) com escores negativos e altamente significativos, pois todos os escores são $\geq 0,50$ (Coelho, 2003). A proporção acumulada entre o primeiro e o segundo componente explicou $80,74 \%$ da variabilidade acumulada, com acréscimo de $18,83 \%$ na proporção acumulada. Para esse componente (CP2), tem-se o destaque para o atributo químico COT nas três camadas, que apresentou escores positivos e altamente significativos, sendo todos acima de 0,90 . 
Quadro 4. Análise de componentes principais (CP) das variáveis analisadas sob sistemas de uso do solo com cultivo de cebola

\begin{tabular}{|c|c|c|c|c|c|c|}
\hline $\begin{array}{l}\text { Componente } \\
\text { da variância }\end{array}$ & CP1 & CP2 & CP3 & CP4 & CP5 & CP6 \\
\hline Autovalores & 11,14 & 3,39 & 1,47 & 0,50 & 0,40 & 0,24 \\
\hline $\begin{array}{l}\text { Variabilidade } \\
\text { explicada (\%) }\end{array}$ & 61,91 & 18,83 & 8,17 & 2,76 & 2,24 & 1,34 \\
\hline $\begin{array}{l}\text { Variabilidade } \\
\text { acumulada } \\
\text { explicada (\%) }\end{array}$ & 61,91 & 80,74 & 88,92 & 91,68 & 93,92 & 95,26 \\
\hline Variável & \multicolumn{6}{|c|}{ Correlação com os componentes principais } \\
\hline ISDMP5 & $-0,89^{*}$ & 0,05 & 0,25 & 0,26 & $-0,17$ & 0,10 \\
\hline ISDMP10 & $-0,89^{*}$ & 0,13 & 0,11 & $-0,17$ & 0,27 & $-0,02$ \\
\hline ISDMP20 & $-0,72^{*}$ & 0,20 & $-0,38$ & $0,39 *$ & 0,28 & 0,17 \\
\hline MACRO5 & $-0,86^{*}$ & $-0,40$ & 0,09 & 0,03 & $-0,09$ & 0,06 \\
\hline MESO5 & $0,95^{*}$ & $-0,11$ & $-0,13$ & 0,04 & 0,14 & $-0,06$ \\
\hline MICRO5 & $0,83^{*}$ & 0,08 & $-0,25$ & $-0,24$ & $-0,01$ & $0,41^{*}$ \\
\hline MACRO10 & $-0,87^{*}$ & $-0,41$ & 0,01 & $-0,11$ & 0,00 & 0,05 \\
\hline MESO10 & $0,94^{*}$ & $-0,18$ & $-0,04$ & 0,17 & 0,13 & $-0,04$ \\
\hline MICRO10 & $0,87^{*}$ & $-0,01$ & $-0,27$ & 0,23 & $-0,20$ & $-0,01$ \\
\hline MACRO20 & $-0,80^{*}$ & $-0,27$ & $-0,48^{*}$ & $-0,07$ & 0,05 & $-0,07$ \\
\hline MESO20 & 0,44 & $-0,40$ & $0,72^{*}$ & 0,12 & 0,27 & 0,06 \\
\hline MICRO20 & $0,96^{*}$ & 0,02 & 0,01 & $-0,03$ & $-0,10$ & $-0,01$ \\
\hline DMP5 & $-0,91^{*}$ & 0,03 & 0,24 & 0,17 & $-0,20$ & 0,06 \\
\hline DMP10 & $-0,95^{*}$ & 0,06 & 0,14 & $-0,21$ & 0,01 & 0,01 \\
\hline DMP20 & $-0,83^{*}$ & 0,16 & $-0,48^{*}$ & 0,02 & 0,06 & $-0,07$ \\
\hline COT5 & $-0,31$ & $0,92^{*}$ & 0,18 & $-0,01$ & $-0,03$ & 0,01 \\
\hline COT10 & 0,07 & $0,99^{*}$ & 0,06 & 0,04 & 0,02 & 0,01 \\
\hline COT20 & 0,20 & $0,93^{*}$ & 0,08 & $-0,05$ & 0,05 & $-0,05$ \\
\hline
\end{tabular}

*Caracteres com maiores cargas fatoriais (escores) selecionadas dentro de cada fator. O critério para classificação foi: valor absoluto $<0,30$, considerado pouco significativo; 0,30-0,49, mediamente significativo; e $\geq 0,50$, altamente significativo, de acordo com Coelho (2003). COT: carbono orgânico total, Micro: microagregados, Meso: mesoagregados, Macro: macroagregados, DMP: diâmetro médio ponderado de agregados e ISDMP: índice de sensibilidade.

Para o componente 3 (CP3), que somado aos CP1 e CP2, explicaram 88,92 \% da variabilidade acumulada; as variáveis com maiores escores foram aquelas da camada de 10-20 cm, sendo MESO20 o atributo que apresentou o maior escore e altamente significativo. Os atributos MACRO20 e DMP20 demonstraram escores medianamente significativos e negativos. Para os demais componentes principais (CP4, CP5 e CP6), houve pouca influência na variabilidade explicada, com menos de $2,5 \%$ para cada componente. Os escores apresentados foram pouco significativos para a maior parte das variáveis correlacionadas com os componentes CP5, CP4 e CP6, sendo apenas observado um escore medianamente significativo para o $\mathrm{CP} 4$ $($ ISDMP20 = 0,39) e CP6 (MICRO5 = 0,41) $($ Quadro 4).
Por meio do diagrama de ordenação construído por meio da análise de componentes principais (ACP), é possível verificar a formação de três grupos distintos, sendo um relacionado ao SPDH (números de um a seis), outro ao SPC (número sete) e a área de mata (número oito). É interessante observar a disposição dos grupos formados, sendo verificado que o SPDH está em oposição ao SPC; e a área de mata está em uma condição intermediária aos demais (Figura 3).

Esse padrão indica o efeito negativo do SPC sobre a agregação do solo, e as variáveis que estão separando o SPC dos demais são os meso e microagregados, presentes em maior proporção no SPC, pois os seus macroagregados apresentam baixa estabilidade física em água (Figura 1). Em contrapartida, no SPDH as plantas de cobertura favorecem os processos químicos, físicos e biológicos, que acarretam na formação e estabilização dos agregados do solo, com ênfase na macroagregação (Figura 1). Dessa forma, têm-se maiores índices de DMP e DMG (Quadro 2), assim como melhores IS (Figura 2) em relação ao SPC, sendo justamente essas variáveis que separaram o grupo formado pelo SPDH (um a seis) da área de mata e principalmente do SPC (Figura 3).

A área de mata, que representa a condição original do solo, separou-se das demais somente por meio do COT (Figura 3). Esse resultado é decorrente dos maiores teores de COT encontrados na área de mata em todas as camadas avaliadas (Quadro 2), pois para as demais variáveis a área de mata apresentou resultados similares para DMP e DMG (Quadro 3) e menores valores de massa de macroagregados em relação ao SPDH. Porém, todas essas variáveis foram menores no SPC em comparação à área de mata.

Em relação ao COT, por meio da ACP, foi possível verificar que se tem maior aproximação do COT com o grupo formado pelo SPDH em comparação ao SPC, com ênfase para o COT na camada de $0-5 \mathrm{~cm}$ (COT5) (Figura 3). Esse padrão indica que a substituição do SPC pelo SPDH recupera os teores de MOS, em razão principalmente da melhoria da agregação do solo, pois o COT fica protegido no interior dos macroagregados formados pela união dos microagregados.

Em estudo sobre a dinâmica da formação e estabilização dos agregados, Tivet et al. (2013) ilustraram as perdas de C nos agregados após a conversão de áreas de floresta nativa para áreas de SPC, com aração e gradagem, sendo que posteriormente pode haver a recuperação desse $\mathrm{C}$ por meio da conversão do SPC para SPD. Esses autores demonstraram que o SPC interrompeu a formação de novos agregados do solo por meio da dispersão das partículas de argila e silte + microagregados de argila; posteriormente, com a substituição do SPC pelo SPD, ocorreu a formação de novos agregados e a redistribuição do $\mathrm{C}$ entre esses agregados por 


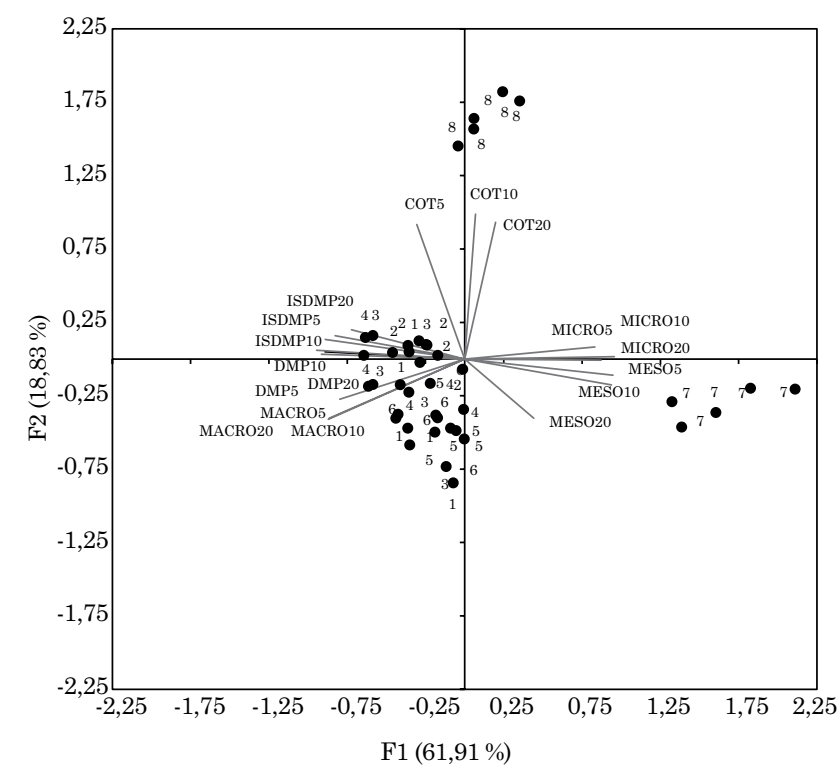

Figura 3. Diagrama de ordenação produzido por análise de componentes principais dos dados coletados. 1 = testemunha, $2=$ aveia-preta, $3=$ centeio, $4=$ nabo-forrageiro, $5=$ aveia + nabo, 6 = centeio + nabo, 7 = convencional, 8 = mata. COT: carbono orgânico total, Micro: microagregados, Meso: mesoagregados, Macro: macroagregados, DMP: diâmetro médio ponderado de agregados e ISDMP: índice de sensibilidade.

meio da entrada de diversos resíduos vegetais. Esses resultados corroboram com os encontrados neste estudo para COT, principalmente na camada de 0-5 cm, e a distribuição dos agregados em macro, meso e microagregados, onde a substituição do SPC do solo pelo SPDH com plantas de cobertura favoreceu a formação de macroagregados estáveis em água, com posterior aumento do DMP, DMG e IS.

\section{CONCLUSÕES}

O uso de plantas de cobertura, solteiras ou consorciadas, no sistema de plantio direto da cebola foi eficiente para recuperar e aumentar os teores de carbono orgânico total (COT) e índices de diâmetro médio ponderado (DMP), diâmetro médio geométrico (DMG) e índice de sensibilidade (IS) em relação ao sistema de preparo convencional; em comparação à área de mata, aumentou o DMG nas camadas de 0-5 e $5-10 \mathrm{~cm}$ de profundidade.

O nabo-forrageiro elevou a agregação do solo (DMG e IS) na camada de 10-20 cm, em relação aos demais tratamentos com plantas de cobertura.

A ACP evidenciou a perda de COT e o aumento dos meso e microagregados no SPC, assim como a substituição do SPC do solo pelo SPDH com plantas de cobertura aumentou a formação de macroagregados estáveis em água, com posterior elevação do DMP, DMG e IS.

\section{AGRADECIMENTOS}

Ao apoio financeiro (Chamada MCTI/MAPA/ MDA/MEC/MPA/CNPq N ${ }^{\circ}$ 81/2013). À Estação Experimental da Epagri de Ituporanga, SC, pela disponibilidade da área experimental.

\section{REFERÊNCIAS}

American Society for Horticultural Science - ASHS. Cover crop mulches tested for no-till organic onions. Science Daily, 2010. [Acessado 27 ago 2014]. www.sciencedaily.com/ releases/2010/04/100421102455.htm.

Angers DA, Caron J. Plant-Induced changes in soil structure: Processes and feedbacks. Biogeochemistry. 1998;42:55-72.

Associação Catarinense de Empresas de Tecnologia - Acate. Agronegócio e tecnologia. Santa Catariana. Anuário 2014. [Acessado 15 ago 2014]. Disponível em: http://www.acate.com. $\mathrm{br} /$ sites/default/files/anuarioacate_0.pdf.

Bezerra RPM, Loss A, Pereira MG, Perin A. Formas de carbono em Latossolo sob sistemas de plantio direto e integração lavoura-pecuária no cerrado, Goiás. Semina: Ci Agrár. 2013;34:2637-54.

Boddey R, Jantalia CP, Conceição PCE, Zanatta JA, Mielniczuk J, Dieckow J, Santos HP, Denardin, JE, Giacomini SJ, Urquiaga SCS, Alves BJR. Carbon accumulation at depth in Ferralsols under zero-till subtropical agriculture. Global Change Biol. 2010;16:784-95.

Bolinder MA, Angers DA, Greegorich EG, Carter MR. The response of soil quality indicators to conservation management. Can J Soil Sci. 1999;79:37-45.

Bronick CJ, Lal R. Soil structure and management: a review. Geoderma. 2005;124:3-32.

Calegari A, Castro Filho C, Tavares Filho J, Ralisch R, Guimarães MF. Melhoria da agregação do solo através do sistema plantio direto. Semina Ci Agrár. 2006;30:147-57.

Casali CA. Sistemas de culturas sob diferentes manejos em longa duração alteram as formas de fósforo do solo [tese]. Santa Maria: Universidade Federal de Santa Maria; 2012.

Coelho AM. Agricultura de precisão: manejo da variabilidade espacial e temporal dos solos e das culturas. Tópicos Ci Solo. 2003;3:259-90.

Comissão de Química e Fertilidade do Solo - CQFSRS/SC. Manual de adubação e calagem para os estados do Rio Grande do Sul e Santa Catarina. 10 ${ }^{\mathrm{a}}$.ed. Porto Alegre: SBCS; 2004.

Costa Jr. C, Piccolo MC, Siqueira Neto M, Bernoux M. Carbono em agregados do solo sob vegetação nativa, pastagem e sistemas agrícolas no bioma Cerrado. R Bras Ci Solo. 2012;33:1-12. 
Coutinho FS, Loss A, Pereira MG, Rodrigues Júnior DJ, Torres JLR. Estabilidade de agregados e distribuição do carbono em Latossolo sob sistema plantio direto, Uberaba, MG. Comunícata Sci. 2010;1:100-5.

Denef K, Six J. Clay mineralogy determines the importance of biological versus abiotic processes for macroaggregate formation and stabilization. Eur J Soil Sci. 2005;56:469-79.

Doneda A, Aita C, Giacomini SJ, Miola ECC, Giacomini DA, Schirmann J, Gonzatto R. Fitomassa e decomposição de resíduos de plantas de cobertura puras e consorciadas. R Bras Ci Solo. 2012;36:1714-23.

Empresa Brasileira de Pesquisa Agropecuária - Embrapa. Centro Nacional de Pesquisa de Solos. Manual de métodos de análise de solos. $2^{\text {a }}$.ed. Rio de Janeiro: 1997.

Empresa Brasileira de Pesquisa Agropecuária - Embrapa. Centro Nacional de Pesquisa de Solos. Sistema brasileiro de classificação de solos. $2^{\text {a }}$.ed. Rio de Janeiro: 2006.

Empresa de Pesquisa Agropecuária e Extensão Rural de Santa Catarina - Epagri. Sistema de produção para cebola: Santa Catarina ( $4^{\mathrm{a}}$ revisão). Florianópolis: 2013.

Gatiboni LC, Kaminski J, Rheinheimer DS, Flores JPC. Biodisponibilidade de formas de fósforo acumuladas em solo sob sistema plantio direto. R Bras Ci Solo. 2007;31:691-9.

Giacomini SJ, Aita C, Vendruscolo ERO, Cubilla M, Nicoloso RS, Fries MR. Matéria seca, relação $\mathrm{C} / \mathrm{N}$ e acúmulo de nitrogênio, fósforo e potássio em misturas de plantas de cobertura de solo. R Bras Ci Solo. 2003;27:325-34.

Golchin A, Oades JM, Skjemstad JO, Clarke P. Soil-structure and carbon cycling. Aust J Soil Res. 1994;32:1043-68.

Gracia RA, Rosolem CA. Agregados em um Latossolo sob sistema plantio direto e rotação de culturas. Pesq Agropec Bras. 2010;45:1489-98

Guedes Filho O, Silva AP, Giarola NFB, Tormena CA. Structural properties of the soil seedbed submitted to mechanical and biological chiseling under no-tillage. Geoderma. 2013;204/205:94-101.

Herlihy M, Mccarthy J. Association of soil test phosphorus with phosphorus fractions and adsorption characteristics. Nutr Cycl Agroecosyst. 2006;75:79-90.

Hermawan B, Bomke AA. Effects of winter cover crops and successive spring tillage on soil aggregation. Soil Till Res. 1997;44:109-20.

Hoorman JJ. Using cover crops to improve soil and water quality. Lima, Ohio: Agriculture and Natural Resources, The Ohio State University Extension; 2009.

Instituto Brasileiro de Geografia e Estatística - IBGE. Levantamento Sistemático da Produção Agrícola. Rio de Janeiro: 2013. v.26. [Acessado 23 abr. 2013]. Disponível em: http://www. ibge.gov.br/home/estatistica/indicadores/agropecuaria/lspa/ lspa_201301.pdf.

Lima Filho OF, Ambrosano EJ, Rossi F, Carlos JAD, organizadores. Adubação verde e plantas de cobertura no Brasil: fundamentos e prática. Brasília, DF: Embrapa; 2014. v.1.

Liu A, Ma BL, Bomke AA. Effects of cover crops on soil aggregate stability, total organic carbon, and polysaccharides. Soil Sci Soc Am J. 2005;69:2041-8.

Llerme NV, Corá EJ, Junior SGP. Influence of soil use on organic carbon and humic substances of an Oxisol in tropical systems. In: Xu J, Wu J, He Y, editors. Functions of natural organic matter in changing environment. Zhejiang (China): Zhejiang University, Press and Springer Science; 2013. p.401-5.

Loss A, Costa EM, Pereira MG, Beutler SJ. Agregação, matéria orgânica leve e carbono mineralizável em agregados do solo. $\mathrm{R}$ Fac Agron Univ Nac La Plata. 2014;113:1-8.

Loss A, Pereira MG, Anjos LHC, Giacomo SG, Perin A. Agregação, carbono e nitrogênio em agregados do solo sob plantio direto com integração lavoura-pecuária. Pesq Agropec Bras. 2011;46:568-76.

Loss A, Pereira MG, Perin A, Anjos L HC. Carbon and nitrogen content and stock in no-tillage and crop-livestock integration systems in the Cerrado of Goias State, Brazil. J Agric Sci. 2012;4:96-105.

Loss A, Pereira MG, Schultz N, Anjos LHC, Silva EMR. Agregação do solo e índice de sensibilidade em áreas sob diferentes sistemas de produção orgânica. In: Anais da $17^{\text {a }}$ Reunião Brasileira de Manejo e Conservação do Solo e da Água. [CD-ROM]. Rio de Janeiro; 2008. Rio de Janeiro: Sociedade Brasileira de Ciência do Solo; 2008 .

Madari BE, Machado PLOA, Torres E, Andrade AG, Valencia LIO. No tillage and crop rotation effects on soil aggregation and organic carbon in a Rhodic Ferralsol from southern Brazil. Soil Till Res. 2005;80:185-200.

Mendes IC, Souza LV, Resk DVS, Gomes AC. Propriedades biológicas em agregados de um Latossolo Vermelho-Escuro sob plantio convencional e direto no Cerrado. $\mathrm{R}$ Bras Ci Solo. 2003;27:435-43.

Monegat C. Manejo de plantas de cobertura do solo em pequenas propriedades. In: Monegat C, editor. Plantas de cobertura do solo: características e manejo em pequenas propriedades. Chapecó: Edição do Autor; 1991. p.146-239.

Nascimento JT, Silva IF, Santiago RD, Silva Neto LF. Efeito de leguminosas nos atributos físicos e carbono orgânico de um Luvissolo. R Bras Ci Solo. 2005;29:825-31.

Oades JM. Soil organic matter and structural stability: mechanisms and implications for management. Plant Soil. 1984;76:319-37.

Panachuki E, Bertol I, Alves Sobrinho T, Oliveira PTS, Rodrigues DBB. Perdas de solo e de água e infiltração de água em Latossolo Vermelho sob sistemas de manejo. R Bras Ci Solo. 2011;35:1777-86

Perin A, Guerra JGM, Teixeira MG, Pereira MG, Fontana A. Efeito da cobertura viva com leguminosas herbáceas perenes na agregação de um Argissolo. R Bras Ci Solo. 2002;26:713-20.

Portugal AF, Costa ODV, Costa LM. Propriedades físicas e químicas do solo em áreas com sistemas produtivos e mata na região da Zona da Mata mineira. R Bras Ci Solo. 2010;34:575-85.

Rilling MC, Mummey DL. Mycorrhizas and soil structure. New Phytol. 2006;171:41-53.

Rosa CM, Castilhos RMV, Pauletto EA, Pillon CN, Leal OA. Conteúdo de carbono orgânico em Planossolo Háplico sob sistemas de manejo do arroz irrigado. R Bras Ci Solo. 2011;35:1769-76.

Salton JC, Mielniczuk J, Bayer C, Boeni M, Conceição PC, Fabrício AC, Macedo MCM, Broch DL. Agregação e estabilidade de agregados do solo em sistemas agropecuários em Mato Grosso do Sul. R Bras Ci Solo. 2008;32:11-21. 
Sisti CPJ, Santos HP, Kohhann R, Alves BJR, Urquiaga S, Boddey RM. Change in carbon and nitrogen stocks under 13 years of conventional or zero tillage in southern Brazil. Soil Till Res. 2004;76:39-58.

Six J, Bossuyt H, Degryze S, Denef K. A history of research on the link between (micro) agregates, soil biota, and soil organic matter dynamics. Soil Till Res. 2004;79:7-31.

Six J, Jastrow JD. Soil organic matter turnover. In: Lal R, editor. Encyclopaedia of soil science. New York: Marcel Dekker; 2002. p.936-42.

Souza M, Comin JJ, Leguizamón ES, Kurtz C, Brunetto G, Müller Júnior V, Ventura B, Camargo AP. Matéria seca de plantas de cobertura, produção de cebola e atributos químicos do solo em sistema plantio direto agroecológico. Ci Rural. 2013;43:21-7.

Tedesco MJ, Gianello C, Bissani CA, Bohnen H, Wolkweiss SJ. Análises de solo, plantas e outros materiais. $2^{\mathrm{a}}$.ed. Porto Alegre: Universidade Federal do Rio Grande do Sul; 1995.

Tivet F, Sá JCM, Lal R, Briedis C, Borszowskei PR, Santos JB, Farias A, Hartman DC, Nadolny Junior M, Bouzinac S, Seguy L. Aggregate $\mathrm{C}$ depletion by plowing and its restoration by diverse
biomass-C inputs under no-till in sub-tropical and tropical regions of Brazil. Soil Till Res. 2013;126:203-18.

Urquiaga S, Jantalia CP, Zotarelli L, Alves BJR, Boddey RM. Manejo de sistemas agrícolas para o sequestro de carbono no solo. In: Aquino AM, Assis RL, organizadores. Conhecimentos e técnicas avançadas para o estudo dos processos da biota no sistema solo-planta. Brasília, DF: Embrapa; 2005. p.257-73.

Vezzani FM, Mielniczuk J. Agregação e estoque de carbono em Argissolo submetido a diferentes práticas de manejo agrícola. $\mathrm{R}$ Bras Ci Solo. 2011;35:213-23.

Vilanova CC. Sistema de plantio direto de cebola: contribuições das plantas de cobertura no manejo ecológico de plantas espontâneas [dissertação]. Florianópolis: Universidade Federal de Santa Catarina; 2010.

Yeomans JC, Bremner JM. A rapid and precise method for routine determination of organic carbon in soil. Commun Soil Sci Plant Anal. 1988;19:1467-76.

Yoder RE. A direct method of aggregate analysis of soil and a study of the physical nature of erosion losses. J Am Soc Agron. 1936;28:337-51. 